BLS 32, No 1 2006. DOI: http://dx.doi.org/10.3765/bls.v32i1.3467 (published by the Berkeley Linguistics Society and the Linguistic Society of America)

\title{
Some Remarks on the Morphosemantics of Multiple Causative Sequences
}

\author{
TYLER PETERSON \\ University of British Columbia
}

\section{Introduction}

There is a diverse array of languages which employ more than one morpheme dedicated to causation. This is not surprising considering the numerous complexities involved in encoding a causative event and all of the linguistic domains it implicates, such as animacy, transitivity, lexical semantics, eventivity, and pragmatics (Shibatani 1976b, 2001; Shibatani and Pardeshi 2002; Dixon 2000). There is a subset of those multiple morphological causative languages in which the causatives can occur simultaneously in a fixed sequence on a verb stem. An example of this is found in the Tsimshian language, Gitksan (Rigsby 1986; Tarpent 1987), and Tarascan, a Mesoamerican isolate (Maldonado \& Nava 2002). Whereas English (1) expresses indirect causation analytically, both Gitksan (2) and Tarascan (3) can achieve indirect causation synthetically through the morphology of 'stacking' causatives on the verb:

(1) English '[Bill had [Gwen frighten Clara]]'

(2) Gitksan ${ }^{1}$

gwin-si-xpts'axw- $\mathrm{t}=\mathrm{s} \quad \mathrm{t}=$ Bill $=\mathrm{t} \quad$ Clara 'as Gwen

CAUS-CAUS-fear- $3=\mathrm{CASE}$ DET $=\mathrm{G} .=\mathrm{DET}$ Clara PREP Gwen

'Bill had Gwen frighten Clara'

(3) Tarascan

Eratzini ché-ra-tara-s- $\varnothing$-ti Yuyani-ni Adrianu-ni

Eratzini fear-CAUS-CAUS-PERF-PRES-IND.3 Yuyani-OB Adrian-OB

'Eratzin had Yuyani frighten Adrian' (Maldonado \& Nava 2002: 181)

\footnotetext{
${ }^{1}$ Special thanks to my Gitksan language consultants, Doreen Jensen, Barbara Sennott and Gwen Simms. Data which is not cited is from original fieldwork, which was supported by The Phillips Fund for Native American Research and the Jacobs Research Fund, awarded to the author. All errors, omissions and misinterpretations of secondary data are mine.
} 
Tyler Peterson

An investigation of these constructions tests a hypothesis which states that, in languages which utilize complex causative sequences, the causative morphemes are uniquely sensitive to the semantics of the stem they attach to along two parameters: (i) the eventuality of the stem, and (ii) the control and/or volitionality of the causee in cases of indirect causation. This generalization has its roots in Dixon (2000:62), who proposes a set of nine partially independent parameters governing causation cross-linguistically, two of which are relevant to this discussion: first, morphological causatives may distinguish between states and actions; second, they may encode degrees of control, volition and affectedness of the causee.

There are two points of interest that come out of this study. This first is that morphology alone cannot be relied upon for the semantic interpretation of multiple-sequence causative structures. This is evident in Gitksan where there are potential mismatches between morphological structure and semantic interpretation when multiple causatives are involved. Secondly, other factors such as animacy and the valency of a predicate to which a causative morphemes attaches might be expected to play an important role in the formation of complex causatives constructions; however, neither appear to be a reliable indicator in predicting the distribution of stacked causatives in these two languages. Tarascan also presents its own challenge, where the causative morpheme -tara, shown in example (3), can only attach to a stem that has already undergone causativization.

Ultimately, multiple-sequence causative constructions reflect the interaction of stative/eventive and volitional/non-volitional distinctions in the causative event they designate. These two notions converge on the subject, and it is shown that complex causative formation is sensitive to the type of subject projected by the verb stem: different causatives select for unaccusative states, which lack a subject; unergative events, in which the subject has the volitionality of an 'actor'; or transitive events, which have agent subjects (Perlmutter 1978; Burzio 1986).

\section{Simplex Causatives}

Both Gitksan and Tarascan have rich causative morphology which allows them to synthetically derive both direct and indirect causation, as well as degrees in between. This section describes and compares the distribution of simplex causatives in Gitksan and Tarascan in terms of what accounts for them: their semantic orientation in terms of the state/action continuum, and the degree of volition or control of the causee. This is schematized in Table 1:

Table 1: Gitksan and Tarascan Causatives

\begin{tabular}{|c|c|c|c|c|}
\hline & Gitksan & Tarascan & Event type & Volition of the Causee \\
\hline Direct & si- & $-\mathrm{ku}-$ & STATES & (No volition) \\
\hline & -in & $\begin{array}{l}\text {-ra- } \\
\text {-ta- }\end{array}$ & EVENTS & Some volition \\
\hline Indirect & gwin- & -tara- & ACTIONS & Most volition \\
\hline
\end{tabular}


Some Remarks on the Morpho-semantics of Multiple Causative Sequences

A note of terminology must be made in this regard: I will reinterpret Dixon's (2000:62) state/action action distinction in terms of STATES and EVENTS, assuming the basic criteria for distinguishing between them. States are unaccusative (atelic) predicates, while events are non-states (Bach 1986). Events may be processes or more simple events, consisting of either unergative or transitive (telic) predicates. ACTIONS are considered subtypes of events, containing the two distinct events that are typically associated with indirect causation: the CAUSING EVENT and CAUSED EVENT (Shibatani 1976). This is also where the highest degree of independence between the subject of the causing event and the subject of the causee event occurs. Maximum volition is also ascribed to the causee subject, as the two events may have little or no temporal or physical overlap (Shibatani 2002). Control refers to the control a subject has over the event or activity denoted by the verb, while volition refers to the degree of 'willingness' the subject has (Dixon 2000:62). While these two notions are crucially distinct in languages such as Korean and Bolivian Quechua, this does not appear to be the case in Gitksan and Tarascan. Therefore, I will use them interchangeably.

\subsection{States, and direct causation}

The Gitksan causative $s i$ - is a verbal prefix which adds one argument to intransitive, (mostly) stative predicates: $s i$ - added to a nominal means to 'cause $\mathrm{X}$ to be in state of existence, process or procure by one's action the affected object signified by the nominal.' (see Belvin 1997:37 for the same characterization of Nisgha'a causatives; Rigsby 1986:350-1), while $s i$ - added to an adjective yields an event that causes someone to be in the state $\mathrm{X}$ :
a. si-'anaax n'iiy'
CAUS-bread $1 \mathrm{sg}$
'I made bread.'

\section{b. si-maay' n'iiy' \\ CAUS-berries $1 \mathrm{sg}$ \\ 'I picked berries.'}
a. 'al'ax $=\mathrm{t}$ Gwen angry $=$ DET Gwen
b. si-'al'ax-ə- $-\mathrm{t}=\mathrm{s}$
$\mathrm{t}=$ Clara $=\mathrm{t} \quad$ Gwen
'Gwen is angry'
CAUS-angry-TR- $3=$ CASE DET $=\mathrm{C} .=$ DET G.
'Clara made Gwen angry.'
'Clara angered Gwen.'

The causative suffix $-k u$ in Tarascan roughly corresponds to Gitksan si-, as both function to introduce an agentive participant, a causer, having direct contact with the patient (Maldonado \& Nava 2002:166). Both take stative complements that transform those states into change of state verbs, yielding a simple event. Compare (5) with (6).

\footnotetext{
a. Eratzini yurhu-tsi-s- $\varnothing$-ti

Eratzin drip.down-MDL-PERF-PRES-IND.3

'Eratzin is slender' (M\&N 2001: 166)
} 
Tyler Peterson
b. Wantanhiata yurhu-s-ku-s- $\varnothing$-ti
Eratzini-ni
Sorrow drip.down-MDL-CAUS-PERF-PRES-IND.3 Eratzin-OBL
'Sorrow made Eratzin skinny' (M\&N 2001: 166 ex. 24)

In all of these cases, the subject of the embedded caused events, paraphrased in English as a small clause Gwen angry and Eratzin slender, is assumed to act with minimal to no volition, as would be expected with patient arguments.

The Tarascan causatives - $r a$ and - $t a$ may also attach to states, yielding a typical inchoative/causative alternation: takusï ura-pi-s- $\varnothing$-ti 'The cloth is white' becomes Valeria ura-pi-ra-s- $\varnothing-t i$ 'Valeria whitened the cloth"2

\subsection{Events, direct/indirect causation and the emergence of volition}

In Gitksan the causative suffix - 'in adds one argument to unergative predicates, functioning to make someone $\mathrm{X}$ by one's (own) hand or action (Belvin 1997; Rigsby 1986:341-3). This can have the effect of deriving direct causation, as the English translation of the example in (7) shows. The original unergative subject, the horses, has been demoted to a patient argument, typical of direct causation, and is naturally presumed to be acting with minimal or no volition. However, (8) represents a case of indirect causation, and this is where we can observe the emergence of volition on the part of the subject of the embedded event, Gwen, whose control over the embedded event is determined by the circumstances of the event.
a. kuxw=hl kyuwatan run=DET horses 'The horses ran away.'
a. $\underline{x}$ sit $\mathrm{t}=$ Gwen vomit $\mathrm{DET}=\mathrm{Gwen}$ 'Gwen vomited'
b. kuxw-'in-y'=hl run-CAUS- 1 sg $=$ DET
kyuwatan horses
'I chased the horses run away.'
b. $\underline{x}$ sit-'in- $\mathrm{t}=\mathrm{s} \quad \mathrm{t}=\mathrm{Bill}=\mathrm{t} \quad$ Gwen vomit-CAUS-3 $=$ CASE DET $=$ B. $=$ DET Gwen 'Bill made Gwen vomit'

A similar situation is found in Tarascan: however, the potential degrees of volition or control are overtly encoded by morphology. Causative $-r a$ and $-t a$ are verbal suffixes which attach to events to yield events with a degree of volition of the subject introduced by the causative. ${ }^{3}$ (9a) is a simple event. In (9b), -ra simply states that the fish was caught, while $-t a$ in $(9 \mathrm{c})$ indicates a greater degree of control the subject introduced by the causativizer has over the event: this fish was not simply caught, but nailed to the wall (Maldonado and Nava 2001:172).

\footnotetext{
${ }^{2}$ There are some cases of $s i$ - attaching to an intransitive verb. However, Belvin (1995) reports that these are marginal or non-productive.

${ }^{3}$ It should also be mentioned that $-k u$, $-r a$ and $-t a$ encode spatial/locative properties in addition to causativization. See Maldonado and Nava's (2001: 172-173) detailed examples and discussion.
} 
Some Remarks on the Morpho-semantics of Multiple Causative Sequences
a. kúchi chá-s- $\varnothing$-ti
atsïmu-rhu
pig penetrate-PERF-PRES-IND.3 mud-LOC
'The pig got stuck in the mud.' (M\&N 2001: 172)
b. ji kurucha-ni chá-ra-s- $\varnothing$-ka I fish-OB penetrate-CAUS-PERF-PRES-IND.1
'I hooked the fish' (M\&N 2001: 172)
c. Eratzini kurucha-ni chá-ta-s- $\varnothing$-ti
Eratzin fish-OB penetrate-CAUS-PERF-PRES-IND.3
'Eratzin nailed the fish (to the wall).' (M\&N 2001: 172)

If Gitksan - 'in, and Tarascan -ral-ta are subcategorized to take event complements, then nothing should prevent them from attaching to transitives. This is borne out in both languages, as event causation in both Gitksan and Tarascan can apply to transitives to yield indirect causation analogous to English make someone $\mathrm{X}$ something:
a. Yuyani urhu-s- $\varnothing$-ti
tsíri-ni
Yuyani grind-PERF-PRES-IND.3 corn-OBL
'Yuyani ground the corn.'
b. Valeria urhu-ra-s- $\varnothing$-ti tsíri-ni Yuyani-ni
Yuyani grind-CAUS-PERF-PRES-IND.3 corn-OBL Yuyani-OBL
'Valeria made Yuyani grind the corn.'
a. hooy-ə-t=s $\mathrm{t}=\mathrm{Gwen}=\mathrm{hl}$ ha'aks use-TR-3 $=$ CASE DET $=$ Gwen $=$ DET bucket 'Gwen used a bucket'
b. hooy-'in-t $=\mathrm{s} \quad \mathrm{t}=\mathrm{Clara}=\mathrm{hl}$ ha'aks 'as $\mathrm{t}=$ Gwen use-CAUS- $3=\mathrm{CASE} \quad$ DET $=\mathrm{C} .=\mathrm{DET}$ bucket PREP $\quad \mathrm{DET}=\mathrm{Gwen}$ 'Clara made Gwen use a bucket.'

The causee subject retains an element of control in the caused event as determined by the context in Gitksan, and with distinct morphology in Tarascan.

\subsection{Actions}

gwin- is the third causative in Gitksan, which is responsible for adding one argument to a transitive or unergative predicate.
a. ts'in=hl hanak' enter $=$ DET woman
b. gwin-ts' in-ə-t=s $\mathrm{t}=$ Gwen $=\mathrm{hl}$ hanak' 'The woman entered' CAUS-enter-TR-3 $=$ CASE DET $=\mathrm{G} .=$ DET woman 'Gwen had the woman come in' 


\section{Tyler Peterson}

When attached to a transitive predicate, the causee is demoted to an oblique while the direct object remains and the causer assumes the subject position. The causee is optional as an oblique, but when expressed, it must act with a high degree of volitionality. Because of this volitionality, gwin- cannot be used with unaccusative predicates, as in (14):

a. hlo'oxs-ə-t $=\mathrm{s} \quad \mathrm{t}=\mathrm{Gwen}=\mathrm{hl}$ hlit

kick-TR-3 $=$ CASE $\quad$ DET $=\mathrm{G} .=$ DET ball

'Gwen kicked the ball'

b. gwin-hlo'oxss-ə-t=s $\mathrm{t}=$ Bill $=\mathrm{hl}$ hlit ('as Gwen)

CAUS-kick-TR- $3=$ CASE $\quad$ DET $=$ B. $=$ DET ball PREP Gwen

'Bill had Gwen kick the ball'

a. t'ugwantxw=hl ts'ak'

fall=DET plate

'The plate fell' (adapted from Belvin 1997: 40)

b. *gwin-t'ugwantxw-ə-t=s $\mathrm{t}=\mathrm{Gwen}=\mathrm{hl} \quad \mathrm{ts}$ 'ak'

CAUS-fall-TR-3 $=$ CASE $\quad$ DET $=\mathrm{G} .=\mathrm{DET}$ plate

'Gwen had the plate fall' (adapted from Belvin 1997: 40)

By comparing gwin- to si- and - 'in, we see that gwin- can only link a subject to a state or event through an intermediary agent, thus deriving a clear case indirect causation similar to English have (Belvin 1997). The situation is similar in Tarascan, which has the causative morpheme -tara dedicated to encoding causation in its most indirect form (Maldonado \& Nava 2002:176). However, -tara is unique in that it requires the presence of other causativization morphology before it can apply. This serves as a convenient point of entry in discussing multiple, complex causative sequences in both Tarascan and Gitksan.

\section{Complex Causative Sequences}

In both Gitksan and Tarascan, the causative morphemes introduced in the previous section can be combined in order to derive more complex causatives. This morphological complexity directly reflects the increasing complexity in event composition (events/states/action) and semantic control (non-volitional/volitional) of the causee.

\subsection{Tarascan}

The Tarascan causative morpheme -tara is similar to gwin- in denoting indirect causation. However there is a restriction on its distribution: similar to gwin-, tara cannot apply to unaccusative stems (although gwin- can attach to unerga- 
Some Remarks on the Morpho-semantics of Multiple Causative Sequences

tives), and it also requires the presence of another causative $-k u$, $-t a$ or $-r a$ to satisfy its selectional requirements, as seen in (15) and (16):

a. *urhu-tara-ni

grind-CAUS-INF

'Make someone grind something' (Maldonado \& Nava 2002: 176)

b. urhu-ra-tara-ni

grind-CAUS-CAUS-INF

'Make someone grind something' (Maldonado \& Nava 2002: 176)

a. Yuyani arha-cha-ku-s- $\varnothing$-ti Adrianu-ni

Yuyani open-mouth-CAUS-PERF-PRES-IND.3 Adrian-OB

'Adrian frightened Yuyani' (Maldonado \& Nava 2002: 181)

b. Eratzini arha-cha-ku-tara-s- $\varnothing$-ti Yuyani-ni Adrianu-ni

Eratzini open-mouth-CAUS-CAUS-PERF-PRES-IND.3 Y.-OB A.-OB

'Eratzin had Yuyani frighten Adrian' (Maldonado \& Nava 2002: 181)

State/event causatives $-k u$, $-t a$ or $-r a$ cannot occur simultaneously on the predicate, but one of them must form a stem with the verb before -tara can apply, thus yielding the morphological template [[V $\{-k u,-t a,-r a\}]$-tara].

In order to explain the specialization of -tara in only attaching to already previously causativized stems, we must follow through on the hypothesis that morphological causativization reflects increasing event complexity and control of the causee subject, and couple it with the selectional restrictions of the individual causatives established above. Thus, we should be able to analyze -tara as subcategorized for taking only event complements. This immediately explains (16), where the (assumed to be) state open mouth, must be turned into an event by $-k u$ in order to serve as a legitimate stem form -tara. However, this has an important implication in that language: we would be forced to claim that Tarascan has only stative (unaccusative) verb roots. Because -tara can't apply to simple transitives, such as gwin- in Gitksan, even transitive events must always be derived. Given the data I've reviewed, this implication is likely not to hold in Tarascan.

An alternative approach is that, while basic eventivity is relevant (-tara can never attach to states), -tara is specialized for the sub-type of events, called ACTIONS. Maldonado \& Nava (2002) present a detailed discussion of the causative -tara, explaining that it 'introduces an extra participant (the causer), letting the actual performer of the action (the causee) function as the second most prominent participant' (p.178). They also go on to explain that -tara is unspecified for volition: it introduces a causer distant enough that the causee subject has almost complete control over the caused event. This is what distinguishes ACTIONS from EVENTS: -tara introduces ACTIONS, which take events as complements. The morpho-semantics of this in Tarascan is represented in (17): 
Tyler Peterson

[[ V-STATES/EVENTS $-k u,-t a,-r a]$ ACTIONS -tara $]]$

\subsection{Gitksan}

Unlike Tarascan, Gitksan causative morphemes can freely combine to form more complex stems, as long as they satisfy their respective selectional restrictions: $s i$ selects for states, - 'in and gwin- for events. The stative/eventive sensitivity in causative formation is evident from the Gitksan example in (2): as with -tara, the causative gwin- can only attach to an EVENT and not a STATE, such as fear. This event is derived by the causative morpheme si-, which takes a state, such as fear, and yields a suitable event stem for gwin- to attach to. However, unlike -tara, gwin- can attach to plain, underived events (cf. (13)).

Volition interacts with eventivity in a non-trivial fashion, as both converge on the semantic characteristics of the subject. Both gwin- and - in can attach to events derived by $s i$-. However, these two morphemes encode different subclasses of events: ACTIONS, which are denoted by gwin-, are events where the causee exerts a higher degree of volition than in simple EVENTS, which are denoted by in. Put another way, in (18) the causee may or may not be interpreted as volitional, while in (19) it must be. This is represented in the - in / gwin- alternation in (18) and (19):

$$
\begin{array}{llll}
\text { si-xpts'axw-'in-t=s } & \mathrm{t}=\mathrm{Gwen}=\mathrm{t} & \text { Bill 'as } & \text { Mary } \\
\text { CAUS-fear-CAUS-3=CASE } & \text { DET }=\mathrm{J}=\mathrm{J}=\mathrm{DET} & \text { Bill PREP } & \text { Mary } \\
\text { 'Gwen made Bill afraid of Mary' } & & \\
& & & \\
& &
\end{array}
$$

In (20), - 'in attaches to the transitive predicate use, forming a suitable stem for the extra 'layer' of indirect causation, achieved by gwin- which introduces an external causer:

$$
\begin{array}{lll}
\text { gwin-hooy-'in- } \mathrm{t}=\mathrm{s} & \mathrm{t}=\mathrm{Bill}=\mathrm{hl} \quad \mathrm{k} \text { 'utaats'=hl hlkutk'ihlkw } & \text { 'as Mary } \\
\text { CAUS-use-CAUS-3=CASE DET=B.DET coat=DET coat } & \text { PREP M. } \\
\text { 'Bill had Mary make the child use a coat' (adapted from Belvin 1995: 41) }
\end{array}
$$

The most complex case is where all three morphological causatives appear on the verb. In these cases, the selectional restrictions of all the causative morphemes must be met: si- derives an event, which serves a suitable stem for in. In the example in (21), this forms the direct causative teach. This is then a suitable stem for indirect causation, provided by gwin- 
Some Remarks on the Morpho-semantics of Multiple Causative Sequences

gwin-si-wilaa-'in- $\mathrm{t}=\mathrm{s} \quad \mathrm{t}=$ Bill=hl Gitksan-imx 'as Gwen

CAUS-CAUS-know-CAUS- $3=$ CASE DET $=\mathrm{B} .=\mathrm{hl}$ Gitksan-lang. PREP G.

'Bill had Gwen teach the Gitksan language'

'Bill had Gwen make someone into the state of knowing Gitksan'

Both - in and gwin- encode event causation, with gwin- encoding a subtype of events, ACTIONS, which are distinguished from regular events in that they assign a higher degree of volition to the causee subject than in plain - in EVENT causation. From this, a morpho-semantic template emerges for Gitksan complex causation:

$$
\text { [gwin-ACTION [[si-STATE-V ] EVENT - in }]]
$$

Notice that ACTION causation is morphologically adjacent to STATE causation, and both STATE and EVENT causation are adjacent to the verb root. This presents a case of a potential morphology-semantics mismatch: the interpretation of multiple morphological causatives is driven not by morphological factors, but rather by eventuality of the stem it attaches to. A clear example is (20), which must be interpreted as having someone make someone use something, and not make someone have someone use something.

\section{In Sum}

Both simplex and complex causative formation in Gitksan and Tarascan are sensitive to (i) the eventivity of the stem they attach to, and (ii) the degree of volitionality assigned to the causee of the embedded causative event. However, what is notable is that these languages diverge slightly in their orientation towards these two parameters: Tarascan makes more productive use of the notion of control, as reflected in its rich causative lexicon distributed across the two eventualities, and less so to the eventuality of the predicate. Gitksan, on the other hand, is sensitive to both the eventuality of the predicate they attach to, and the volition of the causee. This is summarized in Table 2, which shows the distribution of causatives with relation to eventivity, and Table 3, where the notion of causee volition is correlated with the indirect/direct causative continuum:

Table 2: Causatives in Selecting Eventualities

\begin{tabular}{lccc}
\hline \multirow{2}{*}{ STATES } & \multicolumn{2}{c}{ EVENTS } \\
\cline { 3 - 4 } & & SIMPLE & ACTIONS \\
\hline Gitksan & $s i-$ & - in & gwin- \\
Tarascan & $-k u,(-r a,-t a)^{4}$ & $-r a,-t a$ & -tara \\
\hline
\end{tabular}

\footnotetext{
${ }^{4}$ From the data available to me, I'm unable to firmly conclude whether $-r a$, $-t a$ can also attach to states. It's plausible they might, as Maldonado and Nava (2001: 182) claim that $-r a$, -ta may also participate in direct causation.
} 
Tyler Peterson

Table 3: Degree of Causation (adapted from Maldonado \& Nava 2001:182)

\begin{tabular}{lccc} 
& \multirow{2}{*}{ DiRECT CAUSATION } & \multicolumn{2}{c}{ INDIRECT CAUSATION } \\
\cline { 3 - 4 } & & Less Volition & More Volition \\
\hline Gitksan & $s i-,-{ }^{-i n}$ & - 'in & gwin- \\
Tarascan & $-k u,-r a,-t a$ & $-t a,-r a$ & $(-t a)$, -tara \\
\hline
\end{tabular}

Tarascan $-k u$, $-r a$, and $-t a$, and Gitksan $s i$ - take stative (unaccusative) complements to derive simple events, deriving cases of direct causation. Both Gitksan - 'in and Tarascan - $r a$ and -ta take event complements (unergatives or transitives) and can derive either direct or indirect causation. Gitksan has only one causative morpheme - in which has a wider interpretation than Tarascan in terms of both direct and indirect causation and volition (cf. (7) and (8)), which is determined by the context. Tarascan overtly represents this scale of volition through the use of distinct morphemes $-r a$, and $-t a$. The causatives gwin- in Gitksan, and -ta and tara in Tarascan designate complete indirect causation: the causee subject is assumed to be acting with maximal volitionality. They also select event complements to yield a subtype event, ACTIONS.

In the formation of complex causatives sequences, these selectional requirements hold, and in both languages they derive more complex event types from simpler ones. the causatives - 'in and gwin- can only take EVENT complement and not STATE ones, unless they are inherently eventive (i.e. unergatives and transitives) or derived through the application of $s i$. The restriction is even tighter in Tarascan, as -tara can only apply to derived events through previous causativization. We can characterize this in terms of the following continuum in (23), where ACTIONS embed EVENTS which embed STATES:

$$
\mathrm{ACTION} \rightarrow \mathrm{EVENT} \rightarrow \mathrm{STATE}
$$

This continuum is reminiscent of the chain of causality as discussed by DeLancey $(1985 ; 1986)$, adapted in (24):

\section{VOLITION $\rightarrow$ EVENT $\rightarrow$ RESULTING STATE}

(24) represents a series of stages of a single event: an act of VOLITION causes an overt EVENT, which in turn causes a (resulting) STATE. Although not concerned with causation directly, DeLancey analyzes the evidential and perfective/imperfective system of Lhasa Tibetan as morphologically distinguishing between direct knowledge of an EVENT and knowledge of a RESULTING STATE of an event. Neither of these forms encodes the VOLITION stage, which would constitute direct knowledge of the ultimate cause of the event, which is morphologically encoded separately. Volition is implicated in this because EVENT evidentiality cannot encode any control over the event. If any volition is involved on the part of the speaker, they must have direct knowledge of it. When no volition is 
involved, the originating cause is not subject to perception, whereas the actual event of the resulting state may be so.

Although the stages in (23) and (24) are not entirely isomorphic, as volition and events actually overlap in causation, the basic concept holds: volition is always required to accomplish a desire or wish. No decision on the part of the agent/actor to perform an act - volition - can be made without the agent's initial perception of the desire of wish (DeLancey 1985a:5).

Note that in both Tarascan and Gitksan, other parameters such as transitivity and animacy could be expected to condition the selectional restrictions of either simplex or complex causatives. Transitivity is clearly not a factor, as EVENT causatives such as Gitksan - 'in and gwin-, and Tarascan -ta, -ra, and -tara can attach to either transitives or intransitives. Rather, it is the eventivity of the stem, and in particular, the presence of subject which accounts for this fact. Intransitive verbs divide into two groups: unaccusative verbs introduce a theme argument in object position, while unergatives and transitives introduce an actor/agent in subject position. Event causatives require a subject, projected by either and unergative or transitive verb. Conversely, this is what rules out causative morphemes such as $s i$ - from selecting events, and 'action' causation such as -tara and gwin- from selecting unaccusatives.

Also, animacy also does not appear to play a role, as can be seen in (23), where an inanimate causer is introduced by 'in.

$$
\begin{aligned}
& \text { a. wok n'iiy' } \\
& \text { sleep 1sg } \\
& \text { 'I slept' }
\end{aligned}
$$
b. wok-'in $=\mathrm{hl}$
pils n'iiy' sleep-CAUS $=$ DET pills $1 \mathrm{sg}$ 'The pills put me to sleep.'

\section{Multiple Causative Sequences in Other Languages}

Dixon (2000:59-61) reports other languages (see references therein) which allow sequences of causatives. These include languages in which a causative may be reduplicated to render a more specialized, intensive reading, such as in Swahili or Oromo, or a causative of a causative, such as in Capanawa, Kabardian, Hungarian and Turkish. But of relevant interest here are languages such as Nivkh and Apalai, which employ multiple causatives applied to the same stem.

In Nivkh, one morphophonemic and two causativizers, $-u$ and $-g u$, may apply to a verb root to derive both direct and indirect causation: $t$ ' $o z$ - 'go out (i.e. fire); $z o z-u$ 'put out'; t'oz-gu 'let something go out; zoz-u-gu 'make someone put something thing out'. Apalai could be considered similar to Gitksan and Tarascan, as the causative morpheme - $m a$ - is added to the unergative verb eat to yield direct causation in feed. This serves as a suitable complement for the indirect causativizer -po- to apply: otuh- 'eat' (intrans.); otuh-ma- 'feed someone/make someone eat'; otuh-ma-po- 'have someone feed someone/make someone eat".

Both of these languages are suitable candidates for testing the hypothesis presented here: languages that utilize causative sequences are sensitive the eventuality of the stem, and control and/or volitionality of the causee subject. 
Tyler Peterson

\section{References}

Bach, E. 1986. The Algebra of Events. Linguistics and Philosophy 9:5-16.

Belvin, R. 1997. The Causation Hierarchy, Semantic Control and Eventivity in Nisgha. In A. Mendikoetxea and M. Uribe-Etxebarria eds., Theoretical Issues at the Morphology-Syntax Interface, 35-53. Bilbo: Univ. del País Vasco

Burzio, L. 1986. Italian Syntax. A Government and Binding Approach. Dordrecht: Reidel.

DeLancey, S. 1985. Agentivity and Syntax. In Papers from the Parasession on Causatives and Agentivity at the Twenty-First Regional Meeting, Chicago Linguistic Society, 1-12.

DeLancey, S. 1986. Evidentiality and Volitionality in Tibetan. In W. Chafe and J. Nichols, eds., Evidentiality: The Linguistic Coding of Epistemology, 203-13. Ablex.

Dixon, R.M.W. 2000. A Typology of Causatives: Form, Syntax and Meaning. In R.M.W. Dixon \& A. Y. Aikhenvald, eds., Changing valency. Case Studies in Transitivity, 30-83. Cambridge: Cambridge University Press.

Maldonado, Ricardo and E. Fernando Nava. 2002. Tarascan Causatives and Event Complexity. In M. Shibatani, ed., The Grammar of Causation and Interpersonal Manipulation, 157-195. Amsterdam: John Benjamins

Perlmutter, D. M. 1978. Impersonal Passives and the Unaccusative Hypothesis. In Proceedings of the Fourth Annual Meeting of the Berkeley Linguistics Society, 157-189.

Rigsby, B. 1986. Gitksan Grammar. Ms., University of Queensland, Australia.

Shibatani, M. 1976b. The Grammar of Causative Constructions: A Conspectus. In M. Shibatani, ed., Syntax and Semantics 6: The Grammar of Causative Constructions, 1-40. New York: Academic Press.

Shibatani, Masayoshi. 2002. Some Basic Issues in the Grammar of Causation. In M. Shibatani, ed., The Grammar of Causation and Interpersonal Manipulation, 1-22. Amsterdam: John Benjamins.

Shibatani, Masayoshi \& P.Pardeshi 2002. The Causative Continuum. In M. Shibatani, ed., The Grammar of Causation and Interpersonal Manipulation, 85-126. Amsterdam: John Benjamins.

Tarpent, M.-L. 1987. A Grammar of the Nisgha Language. Ph.D. diss., University of Victoria.

Tyler Peterson

Department of Linguistics, University of British Columbia

1866 Main Mall, Buchanan E270

Vancouver, British Columbia V6T 1Z1

Canada

tylerrp@interchange.ubc.ca 